\title{
ENERGY EFFICIENCY SOLUTIONS FOR SUSTAINABLE URBAN MOBILITY: CASE STUDY OF THE MILAN METROPOLITAN AREA
}

\author{
CORINE NSANGWE BUSINGE ${ }^{1}$, SILVANO VIANI ${ }^{1}$, NICOLA PEPE $^{1}$, MARCO BORGARELLO $^{1}$, \\ CARLO CARUSO $^{2}$, GIUSEPPE TRIPODI ${ }^{2} \&$ STEFANIA SORESINETTI $^{2}$ \\ ${ }^{1}$ RSE - Ricerca sul Sistema Energetico S.p.A., Via Rubattino, Milan, Italy \\ ${ }^{2}$ Tandem, Piazza IV Novembre, Milan, Italy
}

\begin{abstract}
In the near future cities will have to supply innovative and high value-added mobility services with respect for environmental, traffic and energy sustainability. It is a great challenge since transportation represents over $20 \%$ of the global energy consumption, $40 \%$ of which is in urban areas. In this context RSE has developed the project STORM (Strategies TOwaRds a sustainable Mobility) which aims to study smart and sustainable solutions and policies in urban mobility planning in order to supply passengers and goods mobility, with respect to economic, energy-efficiency and environmental targets. This paper investigates the impact and benefits of different mobility solutions and policies by applying a multimodal transport model. The Milan area is used as test case for two main reasons: first, its high population density and strong transport offer and second, the large amount of information and data available on passengers' mobility within this area. By assuming that the mobility demand is a constant, 8 mobility scenarios have been tested on the Milan area, which can be classified into two main groups: 4 measures to strengthen the public transport offer; 4 measures to restrict and discourage the use of private vehicles or introduce a relevant share of electric vehicles. Finally, three combinations of these scenarios were made in order to evaluate the impact of a deep and broad transformation of the current mobility trends. For each scenario a cost/benefit analysis was made in terms of energy efficiency, traffic reduction and environmental impact in order to draw up a ranking of the most advantageous and promising measures for urban mobility.
\end{abstract}

Keywords: urban passengers' mobility, transport efficiency, modal split, scenario analysis.

\section{INTRODUCTION}

With increasing urbanization and rapid growth of cities, transport demand is rising over time and impacts on different aspects of urban systems. First of all, time needed for the trip is progressively increasing even for short distances, due to rising traffic densities [1]-[3]. Secondly, the transport sector is energy-intensive with oil as the dominant fuel source and road transport accounting for $81 \%$ of total energy use by the sector. This dependence on fossil fuels makes transport a major contributor of greenhouse gases emission and is one of the few industrial sectors where emissions are still growing [4]. In order to achieve a more sustainable urban mobility, the current passengers transport systems have to change direction and turn towards energy efficiency, environmental sustainability and an overall better quality of urban life [5]. These goals may be achieved by combining two main approaches: (1) technological and infrastructure improvements of both public and private transport, (2) change in passengers' behaviour in terms of a modal shift from private car use to collective/public or non-motorized transport. Various studies have been carried out and each one has focused on a specific strategy for energy conservation and emissions reduction. Some researchers embrace the green economy paradigm and highlight that sustainable mobility is possible when the best technologies are used [6]-[8], investments flow towards efficient transport modes and information systems [9] and policies give clear directions on technology priorities [10]. However, different studies argue that innovative technologies and transport 
infrastructures alone cannot turn mobility to sustainability. In other words, if technology allows us to improve transport efficiency and reduce its impact on the environment, it is also true that behavioural aspects and passenger mobility habits have to be considered, since the success of mobility measures also depends on the acceptability of people [11]-[14]. However it's still hard to decide which strategy is optimal overall and many debates are currently held in the scientific community.

This paper contributes to the existing literature by testing both approaches, (technological/infrastructure improvements and modal shift to collective/public transport), on the case study of Milan Area. The Milan Area was chosen for two main reasons: first, its high population density and strong transport offer and second, the large amount of information and data available on passengers' mobility. Moreover while many studies focus on particular aspects of Milan mobility, such as energy conservation [15], air quality and pollution [16], [17] or passengers' behaviour [18], a comprehensive study that evaluates different mobility strategies under multiple performance indicators is still missing in this area. This paper investigates the performance and impact of 8 mobility measures tested on the Milan area, which can be classified in two main groups: 4 measures to strengthen the public transport offer; 4 measures to restrict and discourage the use of private vehicles or introduce a relevant share of electric vehicles. Finally, three combinations of these measures are made in order to evaluate the impact of a deep and broad transformation of the current mobility trends. For each measure a cost/benefit analysis is assessed in terms of energy efficiency, traffic reduction and environmental impact, in order to draw up a ranking of the most advantageous and promising measures for urban mobility.

\section{METHODOLOGY AND DATA}

\subsection{The transport model}

The transport simulations are based on a multimodal and multi-hour assignment transport model, which was developed using VISUM, a worldwide reference software system for transportation planning, travel demand modelling and network data management. VISUM integrates all relevant modes of transportation, a demand model, a network model and an assignment procedure. For this study, five transport modes were identified and implemented in VISUM simulations: car (regardless of being drivers or passengers), motorbike (regardless of being drivers or passengers), bike, pedestrian, local public transport (bus, trolleybus, tram, subway and railway). The network model is represented by a graph that includes a road network (based on Navteq commercial graph), that allows car, motorbike and pedestrian trips, integrated with information on bicycle lanes and with transit lines (bus, trolley bus and tramway). The railway and the subway are organized as incremental networks, connected with main graph by customized connectors.

Mobility demand is represented by an O/D (Origin/Destination) matrix referring to an average working day (disaggregated over 24 hours): the matrix indicates, for each hour and for each O/D pair, the number of estimated movements of people. For the Milan Area, the $\mathrm{O} / \mathrm{D}$ matrix was obtained from surveys on a sample representative of $10 \%$ of the urban population: globally more than 200.000 people were interviewed [19].

Once the mobility demand is identified at a specific time of day, the next step in the transport model is to identify the percentage of choice for each of the modes of transport considered, or in other terms the modal split. The modal split model considered falls within the multinomial Logit models and estimates the quota of each transport mode based on different utility parameters, mainly related to time (travel time, parking searching time, 
pedestrian time) and trip costs (cost per passenger-km of private car [20], ticket fares [21], parking fare, traffic pollution charge). As the passengers' O/D matrix is obtained by the modal split model, it is assigned to the multimodal transport network in VISUM.

\subsection{The performance assessment of mobility measures}

The multimodal transport model was used to simulate 11 sustainable mobility measures on the Milan case study. The main outputs of the model are the total trips length, both in terms of vehicle-km and passenger-km, for each transport mode, as well as the average speed and total travel time. These parameters are inputs for the energy and environmental assessment of each measure by means of the software COPERT, the EU standard vehicle emissions calculator for emissions and energy consumption for a specific country or region [22]. As regards economic performances, the specific costs reported in the 2016 SUMP of the municipality of Milan have been taken as a reference [23]. In particular, for each mobility measure the investment cost was defined, as well as variations in revenues and operating costs (public transport, parking areas and restricted traffic/pollution zones) incurred by the municipality of Milan, compared to the baseline situation. In order to define the overall financial commitment for each mobility measure, it is assumed that the investment requires a loan to be repaid over 30 years and therefore the annual cost of each measure is defined by the following equation:

$$
A C=I \cdot \frac{i}{1-\frac{1}{(1+i)^{n}}}+\Delta O C,
$$

where $A C$ is the annual cost, $I$ is the investment required to implement the mobility measure, $i$ is the discount rate ( $3 \%$ in this study), $n$ is the duration of the loan (30 years) and $\triangle O C$ is the variation of the operating cost (negative values mean a net income for the municipality of Milan). In order to account for the positive impacts generated by mobility measures to the benefit of society, we define a Net Annualized Cost that rewards those solutions that, given the investment, maximize the energy, environmental and congestion benefits. The Net Annualized Cost is then normalized on the number of passengers daily traveling in the Milan Area, thus obtaining the per capita cost for a more sustainable mobility:

$$
\begin{aligned}
& \text { Net Annual Cost per Passenger } \\
& \qquad=\frac{A C-\Delta \text { Energy }-\Delta C O_{2}-\Delta P M_{2,5}-\Delta \text { Congestion }}{\text { Number of passengers }},
\end{aligned}
$$

where $\Delta$ Energy, $\Delta C \mathrm{O}_{2}, \Delta P M_{2,5}, \Delta$ Congestion represent the monetisation of energy savings, $\mathrm{CO}_{2}$ and $\mathrm{PM}_{2,5}$ emissions avoided, congestion reduction. For the economic assessment of energy savings, Italian electricity and fuel prices were considered [24]-[26], while for environmental externalities and traffic avoidance accounting, studies concerning external costs of transport were taken as reference [27], [28].

\section{THE MILAN AREA CASE STUDY}

\subsection{Overview of Milan Area and the baseline case}

Milan is the second-most populated Italian city and the capital of the Lombardy Region, with 1.35 million people in the city (about 7.400 habitants per $\mathrm{km}^{2}$ ) and other 3.2 million in its metropolitan area (about 2.000 habitants per $\mathrm{km}^{2}$ ). From the administrative point of view, 
Milan Area comprehends the city of Milan and 39 municipalities in its hinterland, as shown in Fig. 1.

During a working day, this area is interested by 7.5 million trips, meanly from inhabitants (80\%) but also from external residents: globally, the population involved amounts to over 3.8 million of individuals [19].

As regards mobility supply, Milan represents a fundamental transport node for the country, being one of the most important hubs for air, rail, road networks, and local public transport. The local public transport consists of 268 surface lines (buses, trams, trolley buses), 4 metro routes and 46 railway stations. ATM, a public limited company owned by the municipality, is the service provider founded in 1931. Its activity cover also the management of car parks, car sharing and bike sharing [29].

In order to identify a reference for the evaluation of the mobility measures, it is necessary to define a baseline case. The baseline case is the representation of actual mobility framework in the Milan Area, obtained by considering fixed demand of mobility and current road and public transport supply. In the baseline case (Fig. 2), the modal split is strongly shifted towards private car, which accounts for $59 \%$ of the trips, followed by a $24 \%$ from the local public transport (hereinafter LPT) and then by pedestrian, bike, motorbike modes with shares of respectively $11 \%, 4 \%$ and $3 \%$. Table 1 shows that $65.2 \%$ of the distance travelled by passengers is attributable to individual motorized transport (car and motorbike), $30.1 \%$ to collective transport and around $4.7 \%$ to non-motorized transport.

As regards final energy consumption, the mobility framework in the Milan Area is responsible overall of 719 toe/y, with a preponderant share of fossil fuels (647 toe/y) and a minor consumption of electricity ( 71 toe/y). The environmental impact assessment through COPERT allows quantifying the main pollutants in $1781 \mathrm{kt} / \mathrm{y}$ of $\mathrm{CO}_{2}$ and $738 \mathrm{t} / \mathrm{y}$ of $\mathrm{PM}_{2.5}$.

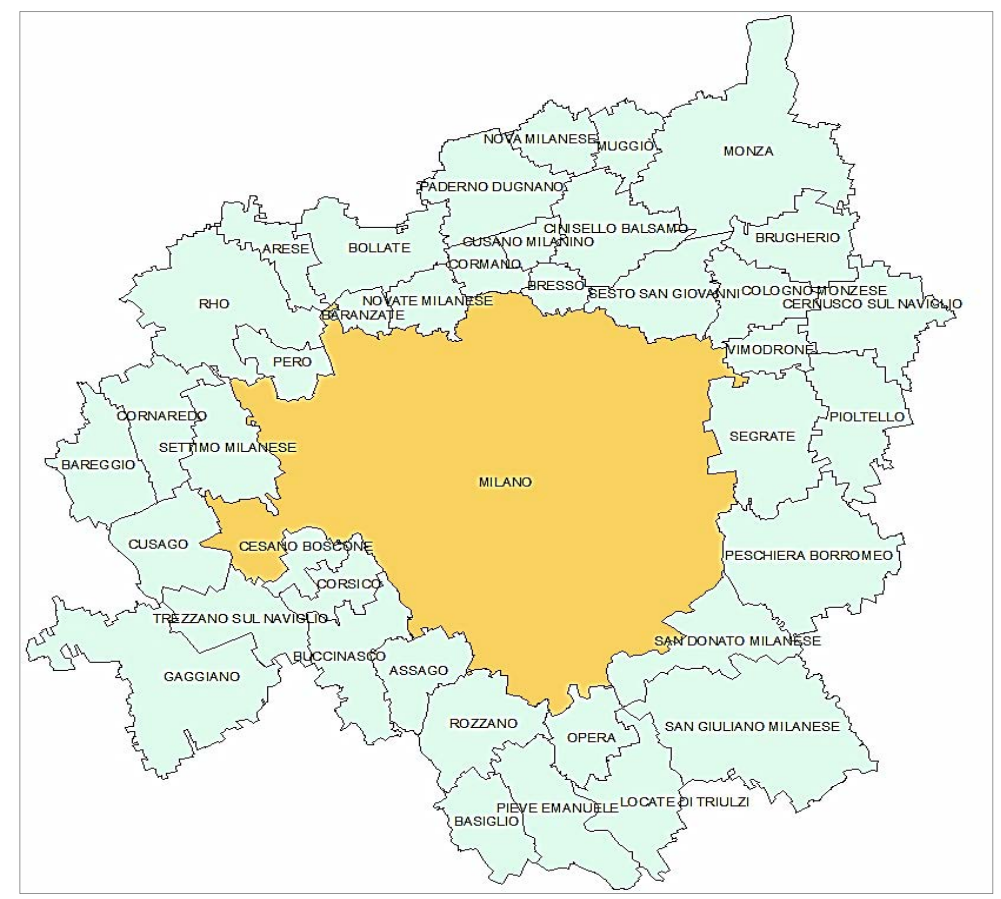

Figure 1: The Milan Area: the city of Milan and the 39 municipalities around it. 


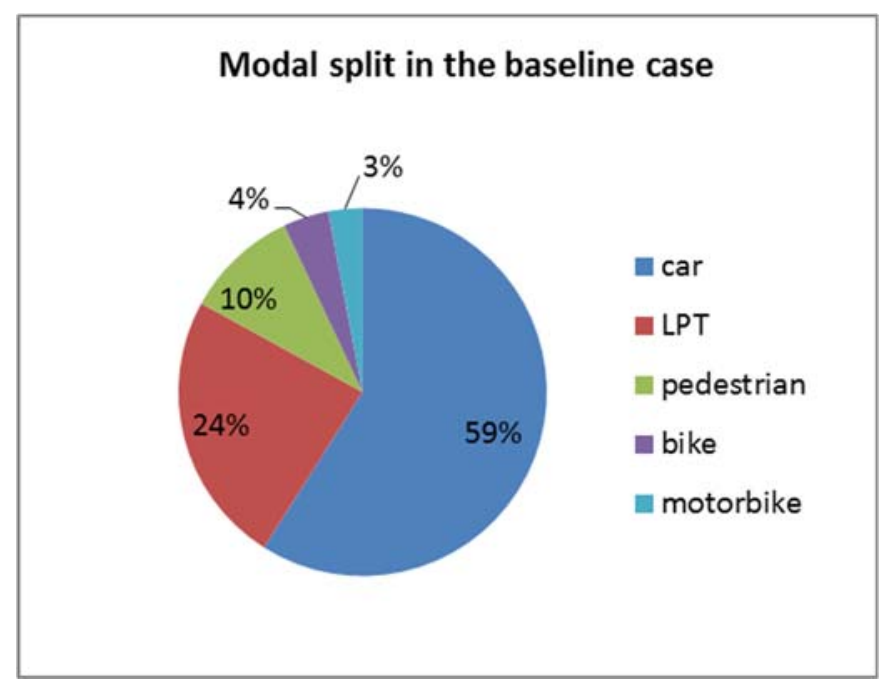

Figure 2: Modal split in the Milan Area baseline case.

Table 1: Distances travelled by passengers and cars in the baseline case.

\begin{tabular}{|l|c|c|c|c|}
\hline \multirow{2}{*}{ Transport mode } & \multicolumn{2}{|c|}{ Passengers transport } & \multicolumn{2}{c|}{ Traffic flow } \\
\cline { 2 - 5 } & Passenger-km & $\%$ & Vehicle-km & $\%$ \\
\hline Pedestrian & 1.513 .976 & $3 \%$ & 1.513 .976 & $5 \%$ \\
\hline Bike & 1.088 .958 & $2 \%$ & 1.088 .958 & $3 \%$ \\
\hline LPT & 16.736 .491 & $30 \%$ & 463.607 & $1 \%$ \\
\hline Car & 34.799 .546 & $62 \%$ & 29.052 .404 & $87 \%$ \\
\hline Motorbike & 1.397 .246 & $3 \%$ & 1.397 .246 & $4 \%$ \\
\hline
\end{tabular}

\subsection{The mobility measures}

In this study 11 different mobility measures have been simulated and tested on the Milan Area with the aim of improving the overall sustainability of mobility under the combined paradigms of traffic reduction, energy efficiency, environmental impact and economic feasibility. In particular the analysis focuses on 8 elementary measures and 3 measures that combine the latter in order to enhance the impact on the mobility framework. Table 2 shows these mobility measures, which can be grouped into two large families: a) strategies aiming at boosting the local public transport (A1, A2, A3, A4, A) and b) strategies aiming at discouraging unsustainable private car use (B1, B2, B3, B4, B). Finally, the measure C-All considers simultaneously all single measures, thus maximising the potential impact on mobility. Note that the two groups actually have the common goal of reducing inefficient mobility habits and promote the modal shift towards collective mobility, both public and private (i.e. Car Pooling). 


\section{RESULTS AND DISCUSSION}

A first glimpse on the impact of the mobility measures is given by Fig. 3: trips by public transport (24\% in the baseline case) increase significantly in A2-Metro (29\%), A4-NoTicket $(35.2 \%)$ and B1-ZTL (30\%) measures. Indeed these measures encourage the use of public transport through different strategies: the strengthening of public transport offer, the drastic reduction of ticket fares, the penalization of individual and polluting transport. The most relevant modal shift is recorded with the combined measures A-Transit and C-All that amplify the effects of individual measures. While public transport increase, private car use decrease from $58.5 \%$ in the baseline case to $47.7 \%$ in B1-ZTL and $49.5 \%$ in A4-NoTicket. One could be surprised by the increase in car travel in B3-CarPooling $(60 \%)$, but it should be recalled that the modal split refers only to the displacement of people and not of vehicles. For a clearer reading of the results, it is indeed necessary to observe distances travelled by people and cars as presented in Fig. 4 and Fig. 5.

The comparison of the distances travelled by people, expressed in passenger-km, shows that LPT passengers increase significantly in the single measures A2-Subway $(+22 \%)$, A4FreeTicket $(+31 \%)$, A3-Railway $(+9 \%)$ and B1-LEZ $(+18 \%)$, while there are minor reductions in B3-CarPooling (-0.3\%), A1-Tram (-0.04\%) and B2-Bike (-0.3\%). The traffic flows, i.e. the distances travelled by vehicles (Fig. 6), face relevant variations in car transport mode, especially in A2-Subway (-10\%), A4-Ticket Free (-12\%), B1-LEZ (-13\%) and B3Carpooling (-17\%). Note in particular that B3-Carpooling, despite a negligible increase in passengers, determines the greatest decrease in cars among single measures, thanks to the $30 \%$ increase in the occupancy ratio. The combined measures generate the highest impact on cars traffic flow, breaking it down by $-20 \%$ in A-Transit, $-28 \%$ in B-e-Move and $-40 \%$ in CAll.

As regards energy efficiency, energy consumption in the Milan Area varies considerably depending on the mobility measure tested (Fig. 6). While weak measures in terms of transport efficiency show an equally weak energy efficiency (-1\% in A1-Tram and $-0,1 \%$ in B2-Bike compared to baseline), energy consumption decreases where there is a considerable reinforcement of public transport offer that moves passengers from inefficient individual transport mode, as it happens in A2-Subway (-6,5\%) and A3-Railway (-3,7\%). This is particularly evident in A4-Free Ticket where, although being the public transport constant, the modal shift from car to LPT saves $12 \%$ of energy consumption compared to the baseline

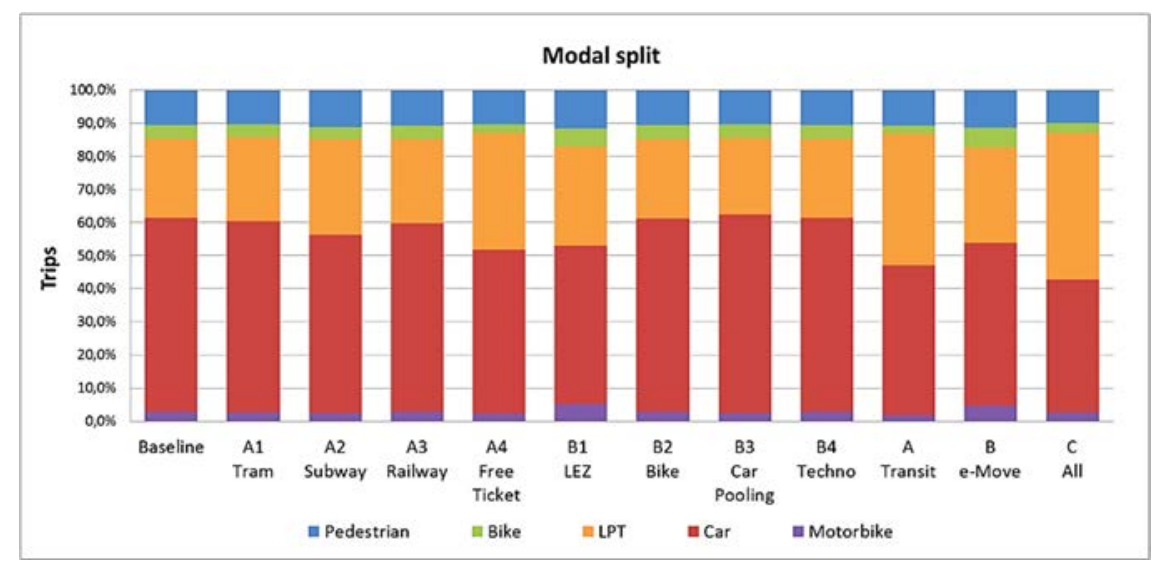

Figure 3: Modal split for the different mobility measures. 


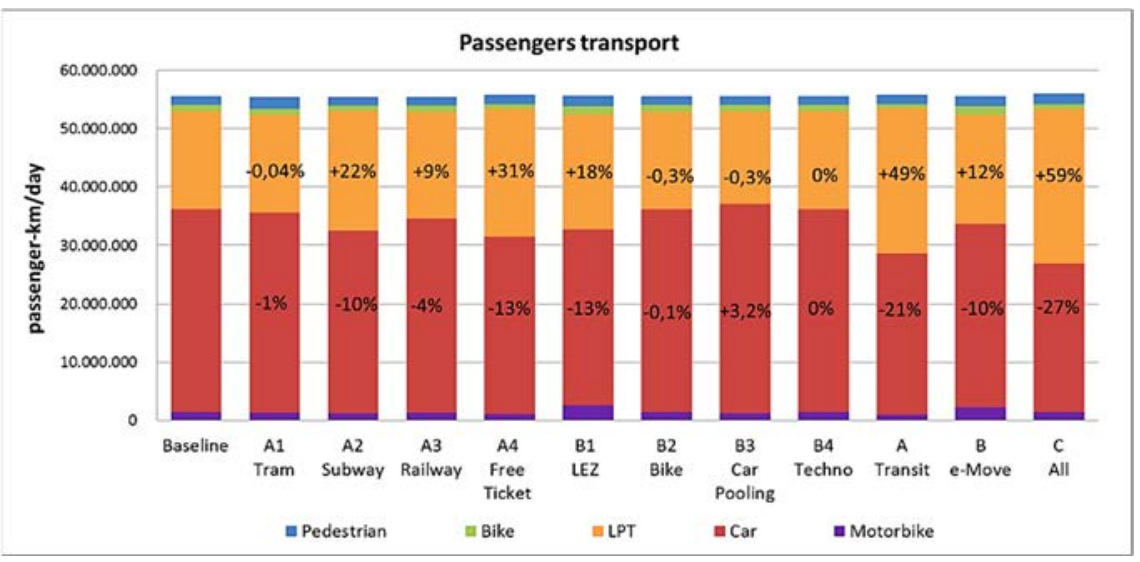

Figure 4: Distances travelled by people for the different mobility measures.

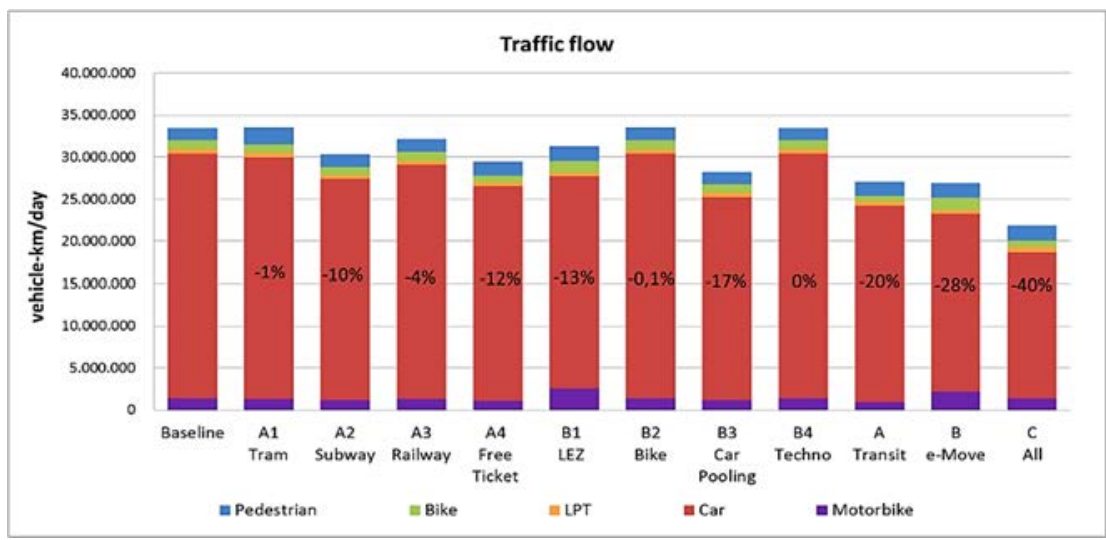

Figure 5: Distances travelled by vehicles for the different mobility measures.

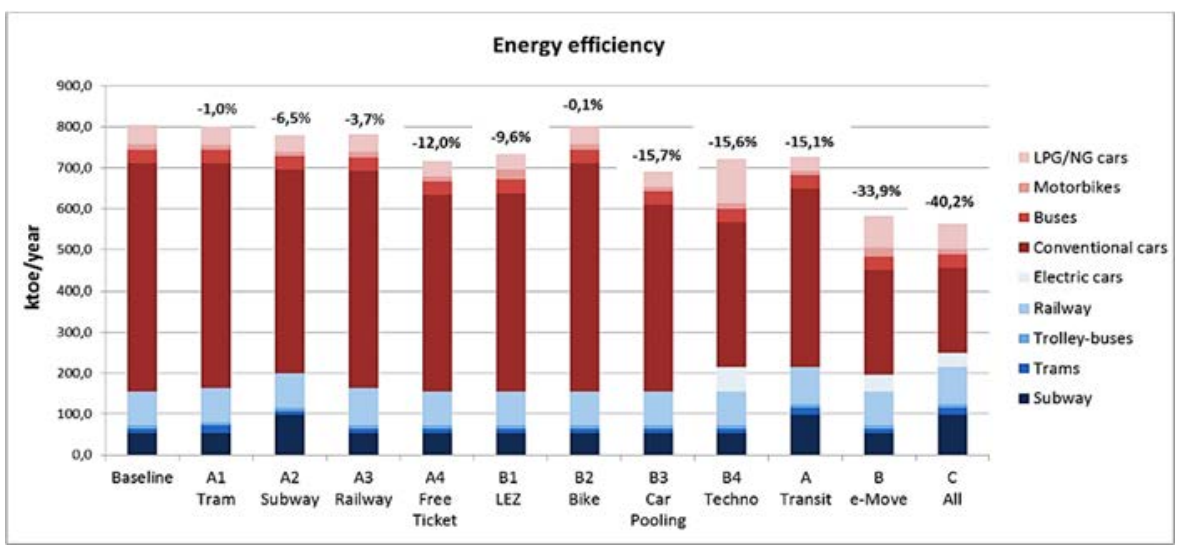

Figure 6: Energy consumption (ktoe/year) and energy savings (\%) for mobility measures. 


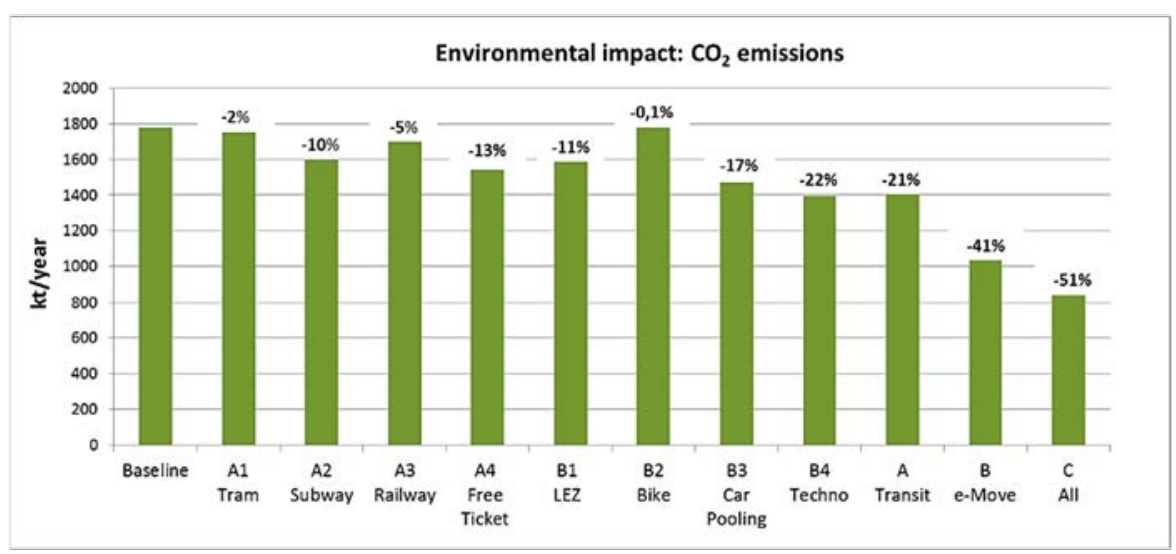

Figure 7: $\mathrm{CO}_{2}$ emissions for the different mobility measures.

case. Measures that disincentive the individual/conventional car show even higher energy performances: B1-LEZ achieves a 9,6\% of energy saving thanks to the ban on the circulation of the most polluting (and energy-consuming) cars, while sharing private car in B3-Car Pooling and introducing greener vehicles in B4-Techno save more than $15 \%$ of final energy consumption. The combined mobility measures show the highest levels of energy efficiency, with up to $40 \%$ energy savings in C-All.

The environmental impact of the different mobility measures is shown in Fig. 7. The overall $\mathrm{CO}_{2}$ emissions savings traces the above-mentioned energy efficiency trend, being a direct consequence of fuels consumption.

The economic assessment is summarised in Table 3, where investment costs and economic value of benefits are reported. The annual cost is higher where heavy investments in transport infrastructures are needed, such as A1-Tram, A2-Subway and the combined measures A-Transit and C-All. The A3-Railway measure is an exception, since the annual cost looks relatively low: this is explained by the fact that the investment to build new railway stations is compensated by significant annual revenues from the increase of passengers taking the train. The A4-Free Ticket measure, though not requiring capital commitments in the public transport offer, determines a substantial loss of revenue for the public transport company ATM and for the municipality itself, which must necessarily be recovered somewhere, presumably by national, regional or local government through taxation or by commercial sponsorship by businesses. Though various studies show the effectiveness of this measure [31]-[33] and many cities are experiencing it worldwide [34], however it is clear that free fare public transport generally implies high costs for society.

The lowest annual costs occur in the category from B1-LEZ to B4-Techno and B-e-Move. The implementation of these mobility measures requires components and civil works which cost is minor order of magnitude compared to public transport costs: cameras and control equipment at the gates of the Low Emission Zone (B1-LEZ); the extension of cycle lanes on existing roads (B2-Bike); the creation of a digital platform for the demand/supply match (B3Car Pooling); incentives for buying cleaner and greener cars (5000€ per car) and charging stations in urban parking lots (B4-Techno). Moreover, the investment for these measures is cut down by annual revenues due to the increase in passengers of public transport. This is the case of B1-LEZ, where the strong restriction to polluting cars pushes people towards public 
transport, to such an extent that revenues from ticketing exceed the investment and generate a net profit of $64 \mathrm{M} € /$ year.

Benefits of mobility measures are also shown in Table 3, alongside with their economic value. Energy savings, environmental externalities avoided $\left(\mathrm{CO}_{2}\right.$ and $\left.\mathrm{PM}_{2,5}\right)$ and congestion reduction have beneficial impact on urban mobility and on local community as a whole. These impacts are converted into positive cash flows that contribute to cut annual costs of mobility measures. This results in the Net Annual Cost per Passenger that, normalized on the number of passengers that gravitate daily in the Milan area, allows us to compare and rank the mobility measures under economic merit criteria (Table 4).

The first five places in the ranking include measures that present a negative NACP, in other words a net gain for the community and the municipality of Milan. These measures generate energy, environmental and congestion benefits that, in economic terms, far exceed the investment cost needed for the implementation. Note that almost all measures at the top

Table 3: Economic assessment of mobility measures.

\begin{tabular}{|c|c|c|c|c|c|c|c|c|c|}
\hline \multirow{2}{*}{ Mobility measure } & \multirow{2}{*}{$\frac{\text { Annual Cost }}{\text { Me/year }}$} & \multicolumn{2}{|c|}{ Energy savings } & \multicolumn{2}{|c|}{$\mathrm{CO}_{2}$ emissions savings } & \multicolumn{2}{|c|}{$\mathrm{PM}_{2,5}$ emissions savings } & \multicolumn{2}{|c|}{ Congestion reduction } \\
\hline & & toe/year & $\mathrm{M} € /$ year & $\mathrm{kt} / \mathrm{year}$ & ME/year & t/year & $\mathrm{k} \in /$ year & $\begin{array}{c}1000 \\
\text { vehicles-km/year }\end{array}$ & M€/year \\
\hline Al -Tram & 165 & 2 & 10 & 30 & 0,17 & 6 & 0,56 & 421 & 0,40 \\
\hline A2 -Subway & 388 & 24 & 71 & 183 & 1,07 & 74 & 7,16 & 2.823 & 2,65 \\
\hline A3 - Railway & 11 & 22 & 47 & 84 & 0,49 & 45 & 4,39 & 1.286 & 1,21 \\
\hline A4 - Free Ticket & 348 & 86 & 138 & 237 & 1,38 & 84 & 8,19 & 3.629 & 3,41 \\
\hline B1 - LEZ & -64 & 69 & 107 & 192 & 1,12 & 100 & 9,72 & 3.920 & 3,69 \\
\hline B2 - Bike & 10 & 1 & 1 & 2 & 0,01 & 0 & 0,04 & 26 & 0,02 \\
\hline B3 - Car Pooling & 30 & 113 & 179 & 309 & 1,80 & 120 & 11,67 & 4.952 & 4,66 \\
\hline B4 - Techno & 30 & 81 & 196 & 385 & 2,25 & 189 & 18,30 & 0 & 0,00 \\
\hline A - Transit & 1066 & 76 & 171 & 373 & 2,18 & 141 & 13,71 & 5.807 & 5,46 \\
\hline B - e-Move & 5 & 222 & 398 & 724 & 4,23 & 297 & 28,81 & 8.016 & 7,54 \\
\hline C - All & 1106 & 239 & 468 & 914 & 5,34 & 362 & 35,08 & 11.718 & 11,02 \\
\hline
\end{tabular}

Table 4: Ranking of mobility measures according to the Net Annual Cost per Passenger.

\begin{tabular}{|c|c|}
\hline $\begin{array}{c}\text { Mobility measures } \\
\text { ranking }\end{array}$ & Net Annual Cost per Passenger \\
\cline { 2 - 2 } & $€ /$ yr/passenger \\
\hline B - e-Move & -106 \\
\hline B1 - LEZ & -46 \\
\hline B4 - Techno & -44 \\
\hline B3 - Car Pooling & -41 \\
\hline A3 - Railway & -10 \\
\hline B2 - Bike & 2 \\
\hline A1 -Tram & 41 \\
\hline A4 - Free Ticket & 54 \\
\hline A2 -Subway & 83 \\
\hline C - All & 164 \\
\hline A - Transit & 233 \\
\hline
\end{tabular}


of the ranking fall in the category of strategies to restrict and discourage the use of private and pollutant vehicles. At the bottom of the table there are mainly interventions to strengthen the public transport offer, as well as the combined measures C-All and A-Transit. For these measures, the benefits, though considerable, are not strong enough to counterbalance the huge capital disbursement for implementation. In fact, public transport projects are among the most expensive public works for local administrations and therefore for the community: consider that the strengthening of public transport involves the acquisition of new, technologically advanced and safer vehicles to satisfy increasing quality expectations from customers; in addition, heavy civil works on roads and underground, as well as the increase in operating and maintenance costs must be considered.

\section{CONCLUSION}

Transport sector represents one of the most relevant challenges in modern society, due to the several aspects that are impacted. In this study passenger transport inside Milan Area is assessed and the impact of different mobility strategies is evaluated. In particular 8 mobility measures are tested on the Milan area, which can be divided in two main categories: 4 measures to strengthen the public transport offer, 4 measures to restrict and discourage the use of private vehicles or introduce a relevant share of electric vehicles. Finally, three combinations of all these measures are made, in order to evaluate the impact of a deep and broad transformation of the current mobility trends. For each measure a cost/benefit analysis is assessed in terms of energy efficiency, traffic reduction and environmental impact, in order to draw up a ranking of the most advantageous and promising measures for urban mobility. Preliminary results seem to suggest that mobility measures that discourage the use of cars and promote the technological evolution towards green cars are more advantageous. This is a consequence of the relatively low investment costs of these solutions, which are even largely balanced by the positive benefits in terms of energy savings, pollutants avoided and traffic reduction. On the other hand, measures in favour of public transport are particularly penalized by the very high investments required to build the infrastructures and to strengthen the circulating fleets. An in-depth examination is needed precisely on these penalized measures, since public transport is able to generate long-term impacts on society and quality of city life (e.g. traffic injuries reduction, increased physical activity and less stress of driving, social inclusion when serving peripheral areas) which are currently difficult to quantify, monetize and then account for in the income statement as positive cash flows. Including this social co-benefits of public transport could therefore change or even overturn the economic ranking of mobility measures.

The outcomes and considerations in this work can be a useful technical-economic tool to support policy makers and local administrations in exploring different targets for urban transport organisation and in choosing the most promising solutions towards sustainable mobility. Moreover policy makers should solicit and help local municipalities to strengthen research on co-benefits and externalities of urban transport, through surveys and interviews with citizens, data collection and monitoring of mobility performance.

The results discussed in the paper suggest interesting opportunities for further research. First, an insight on Car Pooling is currently under investigation, due to low investment costs and high performance in reducing energy consumption, environmental impact and congestion. In particular we are studying Ride Sharing, which is actually the dynamic and real-time evolution of Car Pooling. Secondly, an evolution of public transport in the Milan Area is under examination, from both a technological and a social point of view: the goal is to study the impacts of replacing the buses fleet with green vehicles and define a methodology to quantify the social impacts of public transport. 


\section{ACKNOWLEDGEMENTS}

This work has been financed by the Research Fund for the Italian Electrical System under the Contract Agreement between RSE S.p.A. and the Ministry of Economic Development General Directorate for Nuclear Energy, Renewable Energy and Energy Efficiency stipulated on July 29, 2009 in compliance with the Decree of March 19, 2009.

\section{REFERENCES}

[1] Ross, Z. et al., Noise, air pollutants and traffic: continuous measurement and correlation at a high-traffic location in New York City. Environmental Research, 111(8), pp. 1054-1063, 2011. DOI: 10.1016/j.envres.2011.09.004.

[2] Tsekeris, T. \& Geroliminis, N., City size, network structure and traffic congestion. Journal of Urban Economics, 76, pp. 1-14, 2013. DOI: 10.1016/j.jue.2013.01.002.

[3] Pooley, C.G. \& Turnbull, J., Coping with congestion: responses to urban traffic problems in British cities c. 1920-1960. Journal of Historical Geography, 31(1), pp. 78-93, 2005. DOI: 10.1016/j.jhg.2003.08.019.

[4] Creutzig, F. et al., Transport: a roadblock to climate change mitigation? Science, 350(6263), pp. 911-912, 2015. DOI: 10.1126/science.aac8033.

[5] Szołtysek, J. \& Otrębab, R., Determinants of quality of life in building city green mobility concept. Transportation Research Procedia, 16, pp. 498-509, 2016. DOI: 10.1016/j.trpro.2016.11.047.

[6] Bekiaris, E., Tsami, M. \& Panou, M., A "Greening Mobility" framework towards sustainability. Transportation Research Procedia, 24, pp. 131-136, 2017.

DOI: $10.1016 /$ j.trpro.2017.05.078.

[7] Turton, H., Sustainable global automobile transport in the 21st century: an integrated scenario analysis. Technological Forecasting and Social Change, 73(6), pp. 607-629, 2006. DOI: 10.1016/j.techfore.2005.10.001.

[8] Ausubel, J.H., Marchetti, C. \& Meyer, P.S., Toward green mobility: the evolution of transport. European Review, 6(2), pp. 137-156, 1998.

DOI: $10.1017 / \mathrm{s} 1062798700003185$.

[9] Makino, H., Tamada, K., Sakai, K. \& Kamijo, S., Solutions for urban traffic issues by ITS technologies. IATSS Research, 42(2), pp. 49-60, 2018.

DOI: 10.1016/j.iatssr.2018.05.003.

[10] Foltýnová, H.B. \& Jordová, R., The contribution of different policy elements to sustainable urban mobility. Transportation Research Procedia, 4, pp. 312-326, 2014. DOI: 10.1016/j.trpro.2014.11.024.

[11] Van Exel, N.J.A. \& Rietveld, P., Could you also have made this trip by another mode? An investigation of perceived travel possibilities of car and train travellers on the main travel corridors to the city of Amsterdam, The Netherlands. Transportation Research Part A: Policy and Practice, 43(4), pp. 374-385, 2009.

DOI: 10.1016/j.tra.2008.11.004.

[12] Heinen, E., Are multimodals more likely to change their travel behaviour? A crosssectional analysis to explore the theoretical link between multimodality and the intention to change mode choice. Transportation Research Part F: Traffic Psychology and Behaviour, 56, pp. 200-214, 2018. DOI: 10.1016/j.trf.2018.04.010.

[13] Aini, M.S., Chan, S.C. \& Syuhaily, O., Predictors of technical adoption and behavioural change to transport energy-saving measures in response to climate change. Energy Policy, 61, pp. 1055-1062, 2013. DOI: 10.1016/j.enpol.2013.06.002. 
[14] Garcia-Sierra, M., Van den Bergh, J. \& Miralles-Guasch, C., Behavioural economics, travel behaviour and environmental-transport policy. Transportation Research Part D: Transport and Environment, 41, pp. 288-305, 2015. DOI: 10.1016/j.trd.2015.09.023.

[15] Causone, F., Sangalli, A., Pagliano, L. \& Carlucci, S., An exergy analysis for milano smart city. Energy Procedia, 111, pp. 867-876, 2017.

DOI: $10.1016 /$ j.egypro.2017.03.249.

[16] Cugerone, K., De Michele, C., Ghezzi, A. \& Gianelle, V., Aerosol removal due to precipitation and wind forcings in Milan urban area. Journal of Hydrology, 556, pp. 1256-1262, 2018. DOI: 10.1016/j.jhydrol.2017.06.033.

[17] Colombi, C., Angius, S., Gianelle, V. \& Lazzarini, M., Particulate matter concentrations, physical characteristics and elemental composition in the Milan underground transport system. Atmospheric Environment, 70, pp. 166-178, 2013.

DOI: 10.1016/j.atmosenv.2013.01.035.

[18] Pucci, P., Mobility behaviours in peri-urban areas. The Milan Urban Region case study. Transportation Research Procedia, pp. 4232-4233, 2017.

DOI: 10.1016/j.trpro.2017.05.227.

[19] AMAT, Indagine sulla mobilità delle persone nell'area milanese (2005-2006), 2007.

[20] ACI, Automobile Club d'Italia. Online. www.aci.it/i-servizi/servizi-online/costichilometrici.html.

[21] ATM, Azienda Trasporti Milanesi. Online. www.atm.it/it/ViaggiaConNoi/Biglietti/Pagine/Tipologie.aspx.

[22] COPERT. Online. www.emisia.com/utilities/copert/.

[23] Comune di Milano, Piano Urbano Mobilità Sostenibile Milano, 2015. Online. http://download.comune.milano.it/24_03_2015/Documento\%20di\%20Piano\%20febb raio\%202015\%20(1427206289866).pdf.

[24] ARERA-Italian Regulatory Authority for Energy, Networks and Environment. Online. www.arera.it/it/prezzi.htm.

[25] Italian Ministry of Economic Development. Online. http://dgsaie.mise.gov.it/dgerm/.

[26] Unione petrolifera. Online. www.unionepetrolifera.it/?page_id=480.

[27] RICARDO-AEA, Update of the Handbook on External Costs of Transport, Transport and Environmental Policy Research, 1, 2014.

[28] Holland, M., Pye, S., Watkiss, P., Droste-Franke, B. \& Bickel, P., AEA Technology Environment, Damages per tonne emission of PM2.5, NH3, SO2, NOx and VOCs from each EU25 Member State (excluding Cyprus) and surrounding seas, 1, 2005.

[29] Battarra R., Gargiulo, C., Tremiterra, M.R. \& Zucaro, F., Smart mobility in Italian metropolitan cities: a comparative analysis through indicators and actions. Sustainable Cities and Society, 41, pp. 556-567, 2018. DOI: 10.1016/j.scs.2018.06.006.

[30] ISPRA, 2016 Report on Transports and Mobility. Online. www.isprambiente.gov.it/ files/pubblicazioni/statoambiente/aree-urbane-2016/8_TrasportieMobilit.pdf.

[31] Thøgersen, J., Promoting public transport as a subscription service: effects of a free month travel card. Transport Policy, 16(6), pp. 335-343, 2009.

DOI: 10.1016/j.tranpol.2009.10.008.

[32] Cats, O., Reimal, T. \& Susilo, Y., Public transport pricing policy. Empirical evidence from a fare-free scheme in Tallinn, Estonia. Transportation Research Record, 2415(1), pp. 215-228, 2014.

[33] De Witte, A., Macharis, C., Lannoy, P., Polain, C., Steenberghen, T. \& Van de Walle, S., The impact of "free" public transport: the case of Brussels. Transportation Research Part A: Policy and Practice, 40(8), pp. 671-689, 2006.

[34] Fare Free Public Transport. Online. https://freepublictransport.info/city/. 